\title{
CIBERFEMINISMO O FEMINISMO EN LA RED: Haciendo arqueología en Internet
}

\author{
Almudena GARCÍA MANSO'; ${ }^{1}$ Artenira SILVA E SILVA² \\ ${ }^{1}$ Universidad Rey Juan Carlos, España. ${ }^{2}$ Universidad Federal de Maranao, Brasil \\ almudena.manso@urjc.es, artenirassilva@hotmail.com
}

\section{CYBERFEMINISM OR FEMINISM IN THE WEB: doing archeology on the Internet}

Resumen: Este texto pretende repasar los aspectos más característicos del ciberfeminismo, haciendo especial hincapié en tres reflexiones marginales que están fuera de los límites de las teorías feministas: la realidad ciberfeminista como estrategia subversiva desestabilizadora de la norma de género dual; la necesidad de unión y mantenimiento de la singularidad de los ciberfeminismos y feminismos, y el apoyo en las TICs "juntas gobernaremos la galaxia..."; y la fuerza en la ontología cyborg como estrategia, imagen mítica y política de desestabilización de los géneros "duales y estandarizados". Hablamos de arqueología, pues nos adentramos en una sima, que es toda la información en Internet, nos mostramos abiertos a recoger pistas y a deducir desde la antigüedad de esos datos, la ideología ciberfeminista desde sus orígenes. Tiempos no muy lejanos para las generaciones analógicas, pero tiempos antiguos para las generaciones "millenians". En este trabajo nombramos metafóricamente a la arqueológica como técnica de investigación de un hecho muy antiguo. Aunque en verdad lo que queremos hacer es un recorrido por lo fue el ciberfeminismo, entendido como feminismo para internet y no feminismo en internet.

Abstract: This text aims to review most characteristic aspects of Cyberfeminism, with emphasis on three marginal observations that are outside the limits of feminist theory: the Cyberfeminist reality as a subversive strategy to destabilize the dual gender rule; the need to maintain the unity and the uniqueness of Cyberfeminism and feminisms, and support in ICT "Join me and together we will rule the galaxy..."; and the force in the cyborg ontology as a strategy, policy and mythical image of destabilization of the "standardized" genders. We speak of archeology, which is all the information on the Internet. We are open to collect clues and to deduce from the antiquity of these data the cyberfeminist ideology since its inception. Not isnt too times for analog generations, but is more time for millenians. In this work metaphorically we named archeology as a research technique of a very ancient fact. Although in truth what we want to analyse what was cyberfeminism, understood as feminism for the internet and not feminism on the internet.

Palabras clave: Ciberfeminismo, Netart, Binario, Gender, Ciberespacio Cyberfeminism, Netart, Binary, Gender, Cyberspace 


\section{Comenzamos removiendo}

Las sociedades contemporáneas están expectantes ante el surgir de nuevas formas de representaciones del sujeto. Formas y modelos de representación que se están convirtiendo en campos de cambio y desconfiguración normativa a la hora de considerar lo femenino y la mujer. Estas afirmaciones ya han dejado de tener cierta utilidad ante la invasión vacía de investigaciones, textos y "contextos" que ubican al ciberfeminismo en una simple web institucional de ayuda a las mujeres. Pero eso no erradica la esencia del ciberfeminismo: transgresión y ruptura de los límites sociales del género binario. Algo lejano a las modas de hacer una web o tener un perfil con información feminista. Eso no es ciberfeminismo, ahí no hay acción, sólo información, ahí ni siquiera hay ruptura, sólo un género: el femenino.

Pero Internet sigue siendo un contexto abierto, da cabida a lo que ahora llaman ciberfeminismo -información expositiva, útil para las mujeres, pero que no pretende hacer una red de redes que permita escribir códigos que desbordan los género, códigos Ciborg.

Esas webs, foros, perfiles en redes sociales y hasta grupos de whatsapp -u otras "app" de comunicación móvil, que a partir de ahora les llamaremos "instrumentos de solidaridad", no son en absoluto contrarios al ciberfeminismo, ni al feminismo mismo. Algunos de esos instrumentos no poseen ánimo de voto e ideología "mainstream" política, intenciones y luchas económicas o de poder, son auténticos "instrumentos” contra la otredad de las más vulnerables, contra la precariedad de las mujeres, contra las situaciones de pobreza, de desempleo y contra la violencia y la exclusión, entre otros muchos problemas con los que se encuentran los sujetos sociales mujer/femenino. La era del mega capitalismo productivo y reproductivo, la cultura de masas "masificada", el consumo como ideal de vida y el individualismo (Bauman, 2017a; 2017b ).

Instrumentos que son información y comunicación coeducativa y concienciadora, en ocasiones hasta de servicio social de apoyo y ayuda institucional o de ONGs. Pero que no pretenden mostrar cómo la tecnología Internet puede lograr lo que mejor podría pasar a la sociedad: erradicar el género y cualquier etiqueta que tenga que ver con la identidad sexo/ genérica dual histórica.

Pues "nosotros" somos los residuos de nuestra cultura, de nuestro pasado, de la moral, la conciencia y los actos de aquellos que nos precedieron. Lo cual no es muy favorable a aquel sujeto que se salga de la norma patriarcal: blanco, adulto o joven, capitalista, corporalmente "saludable" y macho. Las mujeres - principalmente aquellas que son solteras, inteligentes, libres, precarias, pobres y vulnerables-, sujetos raciales y coloniales, pobres, niños, ancianos, intelectuales y homosexuales no tienen cabida "en el reino de los cielos". Hacemos uso del neutro, vamos intentando no binarizar, aun sabiendo que en todo este listado de no normativizados, la mujer siempre se ha llevado la peor parte.

Vemos con relativa esperanza que, lo iniciado por las VNS Matrix resistirá. Queremos pensar que cambiarán los tiempos, y con ello las tecnologías, pero la esencia de ese ciberfeminismo ha de permanecer, adaptándose y regenerándose, haciendo ejercicios de comprensión, valorando nuevas formas de acción y abriendo paso a nuevos caminos que, permitan minimizar la idea de subalterna como la mujer binaria, fruto de la política gender y del sistema sexo/genérico.

¿Acaso los escenarios virtuales que recrean la sociedad no son el mantenimiento del régimen binario, cuya escritura es el gender?, los mundos virtuales son el anexo perfecto de la realidad social, espacios de comunicación que hacen de continuum, que mantienen las estructuras y supraestructuras sociales casi intactas, la libertad y el desenfreno que en ellos se puede vivir como "ser sujeto no real" son un mero espejismo, una ilusión, un intento por vivir una vida no vivida pero sí deseada. Ilusiones que si traspasan la frontera de lo virtual, tras una reprogramación de códigos sociales en lo virtual, podrían cambiar los códigos de 
lo fáctico, eso sí sin pasarnos de utópicos, con ayuda de la socialización y difusión cultural, de valores y educativa de esos nuevos códigos, que destruyen la idea de una sociedad sexo/ genérica dual. Pero esto sólo tiene posibilidades de existir si se existe una conciencia del código, es decir de la reprogramación de las identidades y subjetividades (Plant, 1998).

Ahora mismo estaríamos a un paso de conocer realmente lo que es el ciberfeminismo y de ver la cara del ciborg, aunque esa la vemos todos los días frente el espejo:

"Si pisas por aquí estas a salvo pero si pisas por allá explota la bomba ¿Cómo saber si permanecemos a salvo sin detener la marcha? Dentro de nuestros múltiples intentos hemos querido asumir la voz inequívoca de lo femenino, para contraponerla y combatir las vociferantes y omnipresentes definiciones desde lo masculino" (Figueroa, 1991: 123).

Desde el manifiesto de la Zorra mutante de las VNS-Matrix, con sus luchas y búsquedas de nuevos espacios/escenarios "ocultos" de lo femenino y lo feminista sin dualidad, el ciberfeminismo fue extendiéndose, demostrando desde su pluralidad "de ser" que lo femenino también es múltiple, cambiante y a veces contrapuesto. Este incipiente ciberfeminismo hacía uso del Mindware femenino y feminista en un contexto de software, hardware y -por aquella época- de módem. Posteriormente pasaron a lo netartístico - uso de las tecnologías como medio artístico y de reivindicación feminista- tomando como eje central de lucha, existencia y estatus feminista el espacio virtual.

Más tarde llegó la evolución de los Interfaces gráficos, de la masificación de usuarios de Internet, la llegada de las herramientas web2.0. Aquello que podía haberse convertido en su sueño, poco a poco tornó en pesadilla y usurpación. No quedaba lugar para su idea de Mujer-máquina, de ciborg original. La codificación y programación no binaria o codificación inversa, que se deduce de la obra de Sadie Plant (1998), es decir invertir el valor en la programación del cero/femenino/no válido o vacío y del uno/masculino/válido y universal, quedó en ideales, valores, obras de arte y utopías, difícilmente trasladables a la sociedad material. Pues estas ideas de ruptura con lo heteropatriarcal son peligrosas para el sistema, no pueden extenderse y por ello han de ser convertidas en algo minoritario y ser vendido el término ciberfeminismo como la acción de la información "igualitaria" y feminista en la red.

El desafío, y uno de los objetivos del ciberfeminismo inicial, era abrir una brecha en lo considerado normativizado y "normal" de la sociedad contemporánea de la globalización (Martín, 2013): la familia como unidad social generadora de generaciones de reemplazo, La estructura social basada en lo políticamente correcto, en lo capitalista, burgués y acomodado, el capitalismo como la omnipotente y omnisciente economía, el consumo como medio de vida y de ocio, la cultura maintream comercializable y pop; la educación orientada a la producción y reproducción tanto de sujetos como de valores capitalistas y genérico/sexuales basados en la diferencia, discriminación y desigualdad de la mujer, el auge de la moral y los valores "heteronormativos", la política monitorizada por las grandes corporaciones económicas, comerciales y bursátiles -la muerte del ciudadano sufragista-, las tecnologías como espectáculos y objetos de consumo, el terrorismo omnipresente y el poder de la violencia gratuita que se ensañada con los "otros" (Young, 2012), eran los deberes que quería cumplir ese ciberfeminismo combativo. Una suerte de Mr Robot, que nunca fue.

¿Dónde quedaban las mujeres en un mundo tan complicado y hostil, tan lleno de baches y desigualdad, dominado por la tecnología-ciencia, la medicina y biomedicina, la economía capitalista, la información y la política, el consumo como juego de espejos sociales (Bauman, 2010; Baudrillard, 2007) preferiblemente embellecidos por las marcas y su valor social?. 
A las mujeres, a las otredades o minorías sociales como ellas, a las y los feministas sólo les quedaba luchar. Luchar en mundos de morfología digital y morfología fáctica. Pues las discriminaciones y las desigualdades se han ido ocultando tras derechos y techos conseguidos o adquiridos: derecho a trabajar, derecho a votar, derecho a ocupar puestos políticos y administrativos (eso sí de poder limitado y reglado por los "varones blancos angloparlantes"), la existencia de leyes más positivas o menos discriminantes, el derecho a la educación, el acceso a la ciencia -de manera limitada y diferenciada, entre muchos otros avances en materia de paridad. Las muertas siguen estando en las cunetas, el feminicidio es una realidad en el mundo y en incuestionable crecimiento (Segato, 2014, 2016 y 2017) así como los delitos de odio - sea por pertenencia a una raza o etnia, por la orientación sexual, por la identidad de género o por pertenencia religiosa entre otros- así como las violencias invisibles -esas que ahogan pero no son visibles por ser cotidianas- (Bonino, 2005)

Muchos son los frentes abiertos desde el ciberfeminismo más o menos transgresores, subversivos y artísticos, así como muchas han sido sus pioneras y teóricas: las VNS Matriz, Sadie Plant, Donna Haraway, Sherry Turkle, Rosy Stone, por mencionar algunas. Todas ellas representan la pluralidad del ser mujer, de lo femenino y lo feminista, algunas son alteridades, otredades, académicas o artistas, pero todas ellas tenían un común denominador: invertir el código y reprogramar, desde lo ciber hacia lo fáctico.

\section{Lo ciberfeminista...no es un cuento de niños.}

Nos gustaría besar una rana para que se convierta en una pantalla, un ordenador, un ratón y una rápida conexión a Internet, y no para ser princesas en vitrinas del heteropatriarcado. Ese deseo de conversión en el ciberfeminismo era una sugerencia de cómo la tecnología liberaría a la mujer del estereotipo y arquetipo que la hace un ser inmanente, abnegado, subalterno, discriminado y falto de valorización social. La programación invertida, el crear ceros que valen, ciborgs, arte, videojuegos y acciones hacker que remueve conciencias y hace repensar lo binario, reprogramando y programando identidades y subjetividades virtuales que rompan con la norma patriarcal dual del sistema sexo/género, podría demostrar que quizás las ranas que se convierten en príncipes azules nunca debieron existir. Todo esto suponía tocar el código con el que estaba escrito el imaginario social colectivo (Castoriadis, 2013) y el inconsciente social

Ahora, cuando han pasado esas primeras etapas utópicas la estrategia de la que se ha de ir apropiando el ciberfeminismo es la vírica, ser un virus que desde dentro reviente el sistema binario patriarcal. Primeramente se tendría que ir apropiado de las narraciones sociales existentes en los ciberespacios, algo que desde el Net.art lo hace muy bien (Zafra, 2005). Lo femenino se representa, y cómo es representado es lo que importa, al igual que importa para quién es presentado, en el Net.art el sujeto es representado de manera no lineal, al igual que lo femenino, es cambiante, no universal ni idéntico entre sí.

"Puede haber en el alma de las netianas matices más intensos, escondidos y prodigiosos que los colores de una puesta de sol reflejada en el cristal de una prisión. Ninguna combinación arbitraria de palabras podrá representar con rigor esos colores, aunque tal vez en los intersticios digitales de su ambigüedad pueda sugerirles leves destellos de su intensidad como sujeto, de su deseo y de su destino al n(h)acer mujer en Internet" (Zafra, 2005: 23).

La estrategia discursiva del primer ciberfeminismo se centraba en la reflexión sobre la personificación, la feminización y sexualización de las tecnologías, así como la condición subjetiva de la noción de identidad en el ciberespacio. Se creía que en este mundo de planos de realidad ficticios, la identidad era maleable, modificable, sin género o si lo había 
era mutante. El ciborg era la expresión máxima de la identidad en el ciberespacio, su carga política y ética se veía en la ruptura con los límites de la realidad, lo social, lo individual y lo biológico. El carácter de unión híbrida del ciborg -mujer/máquina-, hizo que se generase, por un lado una vertiente únicamente teórica, mientras que por otro lado se generó unas ganas de acción y reacción social más ligada a lo representado y difundido en el Netart y a los movimientos pro tecno-humano del cuerpo futuro, el cual quedaría libre de estereotipos y pre-juicios patriarcales y de gender. Un escenario que reflejaba el deseo por codificar una identidad humano-maquínica vitutal, moldeable, líquida y mutante. "Prefiero ser un ciborg que una diosa" (Haraway, 1995: 311).

Querían construir monstruos, pues esos ciborg no se ceñían a la norma, a lo establecido y a lo puramente humano. Los cuerpos del ciberfeminismo son monstruos, híbridos, preciosos, hipersexuados y a-sexuados, con género o sin género, es esa multiplicidad y mestizaje lo que hace que el ciberfeminismo sea una herramienta útil de acción y lucha.

Son Irónicos y políticos, nacen de la hibridación entre el orden biológico y el orden tecnológico, cuestionando con esta hibridación la noción de realidad, incluyendo por realidad la fábula inventada del gender y la realida impuesta del poder patriarcal

El ciberfeminismo está en continua búsqueda de estrategias discursivas que intentan medrar entre la ironía política y la obtención de nuevos terrenos de expresión y reivindicación, pero no sólo de la noción mujeres. El feminismo precisa de sabia nueva, no puede ser tan restrictivo y excluyente, las mujeres son minorías sociales que deberíamos de tener la conciencia de unión ocn otras minorías que luchasn contra el mismo enemigo, pues el patriarcado también tiende la soga a otredades masculinas (Hooks, 2017).

Sea cual sea el eje de inflexión está en los intentos por configurar un nuevo cuerpo que no tenga marca alguna de lo que fue y es ser mujer o ser otredad -colonial, racial, genérico, temporalmente ubicable, capitalista, reproductivo, productivo, etc-. El cuerpo de la cibercultura es el cuerpo de la acción teórica no del físico-biológico existencial. Un cuerpo sin órganos que esta dotado de conciencia nómada o "resistencia a la asimilación de formas dominantes de las representaciones del yo" (Braidotti, 2000).

El cuerpo ciberfeminista, sus géneros e identidades son la materialización digital del neo-imaginario socio-cultural unido a la ficción y la fantasía, que supone pensar en una sociedad fuera del alcance patriarcal, alejada del gender binario que busca tránsitos de identidad -pues no cree que exista la identidad como noción-, que pretende alcanzar la acción, provocar la reacción vírica y lograr la libertad e igualdad en condiciones y derechos. Ser mujer no es ser gender ni género, el ciberfeminismo pretendería arrancar esas marcas históricas de lo que significa ser mujer, posibilitando desde el poder de la tecnología crear espacios, habitáculos y lugares para esas minorías ciborianas que son mujer y otras otredades. Romper con la idea de la mujer para reemplazarla por el mujeres, múltiple y heterogéneo.

Plant, desde su obra Ceros + Unos y su concepto salvifico de las TICs, concretamente de la informática e Internet, propuso la conexión entre mujeres como un medio lógico, más que necesario y útil para investigar las narrativas de dominación y control, inscriptas en la cultura tecnológica. Todo ello tenía la finalidad de experimentar la potencialidad del ciberespacio, construyendo nuevas formas de identidad y prácticas políticas. Sadie Plant (2005) considera que, desde el ciberespacio se puede desplegar el self, en distintas posiciones del sujeto postmoderno. El sujeto en el ciberespacio se muestra como polimorfo, fragmentado, fluido, digital y en fuga. La consideración del sujeto "digital" o "self digital" en el ciberespacio, posibilitan que Internet sea un escenario de acción, reacción y construcción de novedosas estrategias y posturas, prácticas políticas y de identificación feminista del siglo XXI.

Este despliegue, casi imaginario, de una identidad que roza la ciencia ficción. La identidad virtual de lo femenino, y su potencial visto por Plant. Está en todas las posturas ciberfeministas. Aquellas que se enfocan en el uso de las herramientas de internet como soporte socializador y difusor, y las que lo hacen desde una mayor creatividad y trasgresión, desde 
el ciberpunk, y la figura política del ciborg. Ciberfeminismo de monstruos que están fuera de los límites de la norma, de lo real, de lo físico, de lo biológico y de lo genérico-sexual binario.

Mientras Sherry Turkle analiza los resultados de la unión entre el ciberespacio y las subjetividades, viendo que en esos escenarios de acción social virtual se construyen y despliegan múltiples subjetividades, las cuales se despliegan en múltiples identidades y posiciones de objetividad. Concibe las tecnologías informáticas y el ciberespacio, como un camino hábil para el estudio de la construcción de la identidad y el pensamiento en sí mismo.

Algo similar concibe Salomón, quién hace una analogía entre Windows (múltiples ventanas de apertura y cierre) y la amplitud del "Self" en el ciberespacio. Pero el ciberespacio, la cibersociedad o Internet como escenario de acción, comunicación e interacción social, no sólo permite generar identidades y/o ampliaciones del Self, así como romper normas binarias del gender y permitir existencias ciborg. Internet permite la existencia de "instrumentos" de información y apoyo, esos instrumentos en soporte digital que en ocasiones son confundidos por ciberfeminismo. Pues al ciberfeminismo en múltiples ocasiones le sucede lo mismo que al Netart, la gente confunde el arte para Internet (Netart) que el arte en Internet (arte). El ciberfeminismo es esa corriente, punk, ciboriana y mosntruosa que no se acerca a lo que, podríamos denominar, feminismo en internet (Núñez, 2011). Usar Internet como espacio de exposición de las teorías feministas.

En multitud de ocasiones esos espacios son positivos para el apoderamiento de la mujer y otras minorías sociales, sobre todo en países donde las condiciones de vida no son las mismas que en la vieja Europa. Webs, foros , redes sociales y blogs -también aplicaciones móviles- que generan experiencias políticas, educativas, de ayuda al desarrollo y a la igualdad, a la defensa de la dignidad de las mujeres, a la lucha contra la violencia machista, así como el intento de establecer vínculos de apoyo, lucha e información entre redes de mujeres y otras minorías sociales.

Una situación intermedia a estos límites propuestos por la tecnología se sitúa en la figura del sujeto nómada, delimitado por Rossi Braidotti, una apuesta ubicada tanto en el plano teórico como en el político, que da respuesta -o pretende darla- a la emergencia de las nuevas realidades tecnológico virtuales. Esta subjetividad es el resultado de, ciertos procesos permanentes de desterritorializacion de las codificaciones patriarcales, de corte biologista y por ello racista. La idea del sujeto nómada propone una subjetividad cuyas fronteras son porosas en relación a la alteridad. Subjetividad que se abre a las diferencias que la han configurado, singularizándose mediante un proceso de mestizaje cultural.

Internet es un laboratorio social hábil y significativo para experimentar la construcción y reconstrucción de la subjetividad / self, esta maleabilidad casi ideal se ensombrece al avistar los márgenes de libertad que se da al navegar, comunicar, expresar e introducir información en Internet, las cristalizaciones identitarias y las representaciones de diferencia, alteridad, marginalidad y rechazo, así como la omnipresente cultura patriarcal sigue intacta en la Red.

El desafío es generar experiencias políticas, sociales, culturales y educativas que contribuyan a crear "identidades" que, permitan introducirse en esos contextos de normalidad, atacarlos y contaminarlos víricamente. Sujetos Cyborg, nómades, netianas o demás figuraciones teórico-políticas que permitan acceder a los planos de dominio, contaminarlos y modificarlos. El mooding de género está en los intentos del ciber feminismo, es su arma:

"Mediante un regreso a la raíz del verbo generare, de la que proviene los significados de género, Haraway sugiere la regeneración como posible contraciencia ante los imaginarios tecnológicos y exterminadores fundados sobre violentas fantasías de género" (Orr, en Haraway, 19995: 49). 


\section{Únete a mí, y juntas gobernaremos la cibergalaxia...}

¿Qué es lo que hace de Internet una herramienta hábil para el uso y "abuso" feminista? La capacidad de creatividad, de creación, de reacción, de información, de desinformación, de comunicación, de generar comunidad, de de-construcción, de libre tránsito de todo, de libre elección de todo, "Todo" aquello que es "hacer en Internet y nacer en Internet", desubicación de la norma, re-modificación, educación, ayuda y apoyo, comunidad, subjetividad, multiplicidad, nomadismo, hibridación y mestizaje, quebrantación de los límites de lo corporal y biológico, una salida a la biología y la sexualidad como destino, la negación de la herencia patriarcal, la búsqueda de una cultura, pero Internet también incluye todo aquello por lo que el feminismo lucha.

El ciberespacio, considerado como la galaxia a "gobernar" y las comunidades que en él transitan", están en constante comunicación y conexión. La existencia en estos escenarios está reformulada, pero no por ello debemos caer en el idealismo, el cual cuestiona la existencia de los límites materiales del cuerpo. Éstos límites no desaparecen del todo, se mantienen intactos, puesto que forman parte de la experiencia real humana.

El cuerpo y sus significados son tan importantes que se llega a dar una paradoja: lo más radical del significado del cuerpo se amplifica en Internet, para bien y para mal. Al igual que puede tener cabida el Edén del Ciborg, tiene cabida el machismo, la misoginia, la homofobia y el binarismo genero/sexo tradicional. Las hipérboles del patriarcado y la imposición de las diferencias, desigualdades y discriminaciones son otras realidades digitales, quizás más visibles y omnipresentes que el Ciborg sin marca.

Juntas gobernaremos la galaxia, podría ser una frase llevada a la realidad. La unidad de la pluralidad, el conjunto de "ser ciborgs", las múltiples ideas e identidades de ser mujer como realidad, unidas frente a las disparidades en derechos, opciones y poder.

La galaxia de Internet, con todas sus posibilidades de comunicación y representación, puede ser la escena perfecta para albergar a los feminismos y a los movimientos contrarios a la hegemonía patriarcal.

\section{El mito ...cyborgs del mundo uníos.}

"No se nace mujer: se llega a serlo. Ningún destino biológico, psíquico o económico define la figura que reviste en el seno de la sociedad la hembra humana; es el conjunto de la civilización el que elabora ese producto intermedio entre el macho y el castrado al que se califica de femenino" (Haraway, 2004).

El mito es Ciborg. La representación, creatividad y trasgresión de la norma, de la lógica binaria patriarcal y excluyente. El destino femenino de la mujer no lo marca la "naturaleza", ni su conexión con la maternidad, ni su su íntima relación con la esfera social de lo privado, de lo familiar, de la nutricia. Su valía es la producción y reproducción de un cuerpo colonizado por la mirada masculina y el orden patriarcal capitalista (Segato, 2016). Una vez que la mujer cumple su función natural, sea la maternal, sea la nutricia o la de cuidadora, ella continúa siendo la alteridad, una otredad dominada. Nunca saldrá del círculo de la opresión sino se sitúa fuera de esa esfera de lo natural o "la biología como destino". Parte con una ventaja al abrazar la lógica ciborg, el hombre también está ubicado en la esfera de lo natural.

La salida al callejón del descrédito y subyugación no es otra que la de autoafirmarse desde la cultura, la sociedad y la creación de conocimiento e información, el arte, la literatura y la música, la tecnología y la ciencia, las letras y la filosofía, los medios de comunicación - que siempre han sido dominio del patriarcado-. Para lograr dicho fin una opción posible y muy poderosa es la de abrazar la filosofía del ciberfeminismo. 
Al hilo del pensamiento de Beauvoir (2005) la mujer no nace, se hace, al igual que el resto de seres humanos, la naturaleza no le impone nada. Es la cultura y la sociedad, los intereses del poder lo que determina la situación inmanente de la mujer -y suponemos que de las demás minorías no normativas-.El salir de la esencia femenina y por ello de la inmanencia y de los estigmas que, por defecto, la posicionan en una situación inferior, se consigue únicamente en, con su propio esfuerzo, superar las barreras hasta adquirir el conocimiento y la capacidad necesaria como para poder ser un sujeto trascendente.

Trascendencia que desde el punto de vista de las tecnologías daría la razón al ciberfeminismo. El ciberfeminismo puede materializar el mito y la trascendencia de los sujetosgéneros-otredades a través de la ironía, la trasgresión y su espíritu contestatario, rasgos particulares del movimiento, aunque sea en un plano simbólico, y en ocasiones artístico. Da alas a las mujeres y otredades a poder ser libres y romper sus moldes normativos, aunque sea en un plano simbólico, de tanto reiterar y performativizarlo se termina materializando. Ejemplo de ello lo tenemos en las personas que no se identifican en ningún género, o aquellas que han querido ampliar sus sentidos con una prótesis tecnológica. "la apoteosis del simulacro, entendido como copia que carece de original, para vivir una vida eterna" (Aguilar García, 2008: 90).

La lógica del ciborg parte de la posición política a la que aludía de Beauvoir, entendida en este caso como el poder de la tecnología y de la auto-construcción de la subjetividad. Pues el ciborg es "un sujeto revolucionario construido, porque sólo él puede otorgarnos una posición política" (Haraway, 1995: 269). La ciborización no es más que La posición política del Cyborg que se ubica en el simulacro y en la desestabilización de las parejas metafísicas, incluyendo en esas parejas el dualismo de género y sexo. Todo ello permite el "cierre metafísico de identidad" una acción que provoca que el género quede atrapado en un sexo y una identidad que no conduce al discurso de emancipación feminista (Haraway, 1995: 264).La fluctuación en la lógica del cierre metafísico, de la identidad de género niega las identidades clasificadas - por género, por raza, por condición corporal, por situación capital-. Es una burla al lenguaje del código único, un código como hemos visto basado en lo binario sexo/ genérico, animal/humano, máquina/humano, además de desestabilizar el orden patriarcal centrado en la producción y reproducción y en la naturaleza/biología como destino.

"El cyborg no reconocería el jardín del Edén" (Haraway, 1995: 256) pues ha roto la lógica tradicional de la dualidad eterna. De la creencia del origen como algo natural.

La esfera de acción de las identidades cyborg, las hijas bastardas de la dualidad de género, es la esfera más simulacro, más virtual, más artefacto, más inmaterial pero más creativa y más interactiva en tiempo real. Su lugar es Internet, su escenario la ironía, la reiteración de la norma hasta transgredirla y generar la ironía o ruptura de expectativas por parte del que mira, ve e interpreta, siendo su lógica la de la performatividad (Butler,2008).

Pero no todo es el cuento de hadas que pretende ser. Al igual que en todas las propuestas lanzadas desde cualquier ideología, idea, filosofía u ontología existen vertientes detractoras y vertientes defensoras. Si el ciberfeminismo -el feminismo para internet- considera al ciberespacio como demiurgo hacedor de las identidades fluidas, sin límites, marginales y ajenas al dualismo de género, la vertiente tecnofóbica defiende que el ciberespacio es un mantenedor y amplificador de los rasgos, marcas y estereotipos androcéntricos y patriarcales. Siendo un escenario más de sometimiento y subyugación. Ziauddin Sardar (2000) considera que el ciberespacio es una neocolonización de occidente, creada por el poder de siempre: varones blancos de clase media, con intereses meramente económicos y pornográficos. "la mitad del ciberespacio que no es comercial es mayoritariamente pared de retrete" (Sardar, 2000: 741).

En el ciberespacio cabemos todos, no podemos negar que las palabras de Sardar tienen mucho de verdad. El mantenimiento de la hegemonía macho/blaco/clase media y la continuidad de los estereotipos de género machistas. Pero al ser un anexo a la realidad social, permite la integración de todos los planos de realidad en un mismo espacio. 
La representación de esas posibilidades que se establecen desde el ciberespacio es la estrategia que rebate las posturas de Sardar. El ciberespacio ni es demasiado bueno ni es lo peor, es lo que es: un escenario social más, pero de naturaleza virtual, que muestra información a un muy amplio público, el cual interacciona y vive esa interacción como real, puesto que es real. Lo que sucede en Internet afecta a la vida real de los sujetos, sea para bien o para mal, las realidades del mercado negro y venta de productos ilícitos vía ciberespacio es un hecho tan real como que existe la transgresión de los binarismos genéricos y la posibilidad de programar en código inverso.

Mucho ha pasado desde sus orígenes en 1997 con dos acontecimientos sin igual, la publicación del Manifiesto de la Zorra Mutante por el grupo ciberfeminista VNS Matrix y la Primera Internacional Ciberfeminista que tuvo lugar en la Documenta X de Kassel donde se dio forma y lectura al Manifiesto para ciborgs. No podemos olvidar que éste es feminismo para Internet no feminismo en Internet.

\section{Crítica positiva a los feminismos}

A modo de conclusión, parándonos a pensar en lo que es históricamente el ciberfeminismo - una historia breve, como todo en la sociedad capitalista actual- y el ejercicio arqueológico de ir tomando sus puntos de referencia para analizarlos y dar forma a su historia, vida y cultura.

$\mathrm{Su}$ cultura, libre y cambiante, irónica y performativa, centrada en lo creativo y en lo transgresor y su acción y forma de vida la del video juego, la de las identidades virtuales, la de la programación y código invertido y no binario, contando con su expresión más duradera que es el Netart activista y el hackeo activista, vemos que hay un mundo entre lo que muchos y muchas llaman ciberfeminismo, una web de mujeres, un espacio feminista, un blog con noticias, una red social para aportar ideas, o una plataforma educativa y el ciberfeminismo como feminismo para internet, pues este tipo de acciones que, desde una arqueología elemental, hemos analizado sin detenernos en exceso. Sitúan al ciberfeminismo fuera de las acciones de los feminismos de corte tradicional, ubicados en las élites -tanto académicas como económicas-, los feminismos de la igualdad y de la diferencia los cuales siguen en los entramados del género, los feminismos ultra ortodoxos, aquellos que no conciben otredades más que a la propia mujer.

La historia social nos ha puesto ante nosotras muchos otros tipos de otredades, algunas mejor vistas que las mujeres, otras igualmente invisibilizadas. La sociedad nos ha discriminado a todos por igual, aunque sí es cierto que el ensañamiento mayor es contra la mujer. Esa misma historia social nos puede hacer ver que feminismos hay muchos, que otredades hay varias y que aceptar a compañeros y compañeras de batalla y lucha no es una mala estrategia.

Es la historia social la que nos ubica en una sociedad patriarcal, y que posiblemente el futuro de esa historia social nos quite la razón, y esas otras minorías nos traicionen, al igual que sucedió con el derecho al sufragio universal en Estados Unidos o en la Revolución Francesa. Pero el feminismo debe ser de todos, además de comprender la necesidad de ir quitando etiquetas o marcas a los sujetos sociales, gender nunca debió haber nacido, nunca tenía que haber sido elevado como etiqueta social, pues aunque visibilizó la mala situación de las mujeres, también las ubico como las vulnerables, las otras dentro de un binarismo que, si bien ya existía -sexo masculino / sexo femenino-, generó mayor diferencia, con ello discriminación y así hasta llegar a la desigualdad.

La sociedad dividida y categorizada en dos sólo mantiene las mayores discriminaciones y desordenes en derechos humanos. Haciendo honor a la transgresión quizás sea eso por lo que el ciberfeminismo vislumbro un rayo de luz en la posibilidad de programar de nuevo la historia de los sujetos, quitando el patriarcado como poder y el dualismo como sistema. 


\section{Bibliografía}

Aguilar García, T. (2008). Ontología Cyborg. Barcelona: Gedisa.

Baudrillard , J. (2009). La sociedad de consumo. Sus Mitos, sus estructuras. Madrid: Siglo XXI.

Bauman, Z. (2010). Mundo Consumo. Madrid: Paidós Iberica.

Bauman, Z. (2017a). La sociedad sitiada. Madrid: Fondo Cultura Economico

Bauman, Z. (2017b). La globalización. Consecuencias Humanas. Madrid: Fondo Cultura Economica Beauvoir, S. (2005). El segundo Sexo. Madrid: Cátedra.

Bonino, L. (2005). Las microviolencias y sus efectos: claves para su detección, en Ruiz-Jarabo, C;

Blanco, P. (Coords), La violencia contra las mujeres: prevención y detección. Madrid: Díaz de Santos

Braidotti, R, (2000). Sujetos nómades. Buenos Aires: Paidós.

Butler, J. (2001). El género en disputa. El feminismo y la subversión de la identidad. Buenos Aires, Paidós.

Butler, J. (2008). Cuerpos que importan. Buenos Aires: Paidós-Argentina.

Castoriadis, C, (2013). La institución imaginaria de la sociedad. Barcelona: Tusquest.

Figueroa, H. (1991) The Cyborg Handbook. London: Routledge.

García Manso, A. (2015). ¿Normas y Géneros?: performatividad en Judith Butler y la teoría ciberfeminista. Revista Latina de Sociología. 6 (2), 76-115.

Haraway, D. (1995) Ciencia, Cyborgs y Mujer. La reinvención de la naturaleza. Madrid: Cátedra.

Haraway, D. (2004) Testigo-Modesto@.Segundo-Milenio.HombreHembra_Conoce_Oncoraton. Feminismo y tecnociencia. Barcelona: UOC.

Hooks, B. (2007). El feminismo es para todos. Madrid: traficantes de sueños.

Martín-Cabello, A. (2013). Sobre los orígenes del proceso de globalización. Methaodos Revista De Ciencias Sociales, 1(1). doi: 10.17502/m.rcs.v1i1.22

Núñez, S. (2011). Prácticas del ciberfeminismo. Uso y creaciones de identidadeds en la red cono nuevo espacio de relación. Madrid: Instituto de la mujer.

Plant, Sadie (1998). Ceros + Unos. Mujeres digitales + la nueva tecnocultura. Barcelona: Ediciones Destino.

Sardar, Z. (2000). "Alt Civilizations. Faq. Cyberespace as the darker side of the west" en Bell, D. y Kennedy, B. (eds), The Cybercultures Reader. Londres: Routledge, 741

Segato, R. (2014). La escritura en el cuerpo de las mujeres asesinadas en Ciudad Juárez. Buenos Aires: Tinta Limón.

Segato, R. (2016). La guerra contra las mujeres. Madrid: Traficantes de sueños.

Segato. R. (2017b). Las estructuras elementales de la violencia. Barcelona: Prometeo.

Sibilia, P. (2005). El hombre postorgánico. cuerpo, subjetividad y tecnologías digitales. México: Fondo Cultura Economico.

Young, J. (2012). El Vértigo de la Modernidad Tardía. Buenos Aires: Didot.

Zafra, R. (2005). Netianas. N(h)acer mujer en Internet. Madrid: Lengua de Trapo. 